\title{
The effects of five weeks of kickboxing training on physical fitness
}

\author{
Ibrahim Ouergui ${ }^{1}$ \\ Nizar Hssin ${ }^{1}$ \\ Monoem Haddad ${ }^{2}$ \\ Johnny Padulo 3,4 \\ Emerson Franchini 5,6 \\ Nabil Gmada ${ }^{1}$ \\ Ezzedine Bouhlel ${ }^{7}$
}

1 Research Unit "Athletic performance and physical rehabilitation" of the Higher Institute of Sport and Physical Education Kef, University of Jendouba, Tunisia

2 Sport Science Program, College of Arts and Sciences, Qatar University, Doha, Qatar

3 Sport Science, University e-Campus, Novedrate, Italy

4 Tunisian Research Laboratory "Sports Performance Optimization" National Center of Medicine and Science in Sport (CNMSS), Tunis, Tunisia

${ }^{5}$ Martial Arts and Combat Sports Research Group, School of Physical Education and Sports, University of Sao Paulo, Brazil

${ }^{6}$ Faculty of Sports Sciences, University of Montpellier, France

7 Laboratory of Physiology, Faculty of Medicine of Sousse, University of Sousse, Sousse, Tunisia

\section{Corresponding author:}

Johnny Padulo

Sport Science, University e-Campus, Novedrate

Via Isimbardi, 10

22060 Novedrate, Italy

E-mail: sportcinetic@gmail.com

\section{Summary}

Aim: the purpose of this study was to examine the effect of kickboxing training on physical fitness.

Methods: 30 subjects were randomized into a kickboxing-group $(n=15)$ and control group $(n=15)$. Each group trained approximately 1-hour per day, three-times per a week during five weeks. Musclepower (upper-body: bench-press-test, medicineball-test; lower-body: squat-jump and countermovement-jump-test), flexibility, speed and agility, aerobic (progressive maximal exercise test), anaerobic fitness (Wingate test) and body composition were assessed before and after the training period. Results: the kickboxing group showed significant improvement $(p<0.05)$ in upper-body muscle power, aerobic power, anaerobic fitness, flexibility, speed and agility after training whereas body composition, squat jump and counter movement jump (height, power and velocity components) did not change for both groups.

Conclusion: kickboxing-practice was effective to change many physical variables. Thus, this activity can be useful for enhancing physical fitness, but complementary activities and/or nutritional interventions should be necessary.

KEY WORDS: aerobic fitness, body composition, combat sport, muscles performance.

\section{Introduction}

It has been suggested that martial arts and combat sports can have positive effect on physical fitness and health ${ }^{1,2}$. The effect of martial arts and combat sports practice (i.e., Judo, Taekwondo, Karate) was investigated in several studies among youth ${ }^{3,4}$, adolescents ${ }^{5,6}$, elders ${ }^{7-9}$ and people suffering from some disorders (e.g., developmental coordination disorder, multiple sclerosis $)^{10,11}$. Most of these studies reported that martial arts and combat sports training involved a significant improvement in physical and motor abilities. However, only a few longitudinal studies confirmed its benefits to health-related physical fitness variables ${ }^{12,13}$. Tsang et al. ${ }^{12}$ reported that three 1hour kung-fu session per week during half an year did not result in significant different impact over healthrelated anthropometric variables and body fat (estimated via Dexa) compared to tai-chi-chuan "placebo" group. Conversely, Yoshimura and Imamura ${ }^{13}$ reported absolute and relative $\mathrm{VO}_{2 \mathrm{MAX}}$ increases in women taking part in a 30-min basic karate session conducted four times per week during 10 weeks. However, no change was observed in the control group. Thus, the benefits of martial arts training programs on physical fitness are controversial.

As in karate, the kickboxing training session involves basic skills, combination exercises and sparring drills ${ }^{14}$. Recently, Jackson et al. ${ }^{11}$ investigated the kickboxing training effects on balance and mobility impairments among people with multiple sclerosis (MS) and demonstrated that it can be a feasible activity to improve balance and mobility for individuals with MS.

Except for the study of Jackson et al. ${ }^{11}$, there is no other published study that has focused on examining 
the effect of kickboxing regimen training on different physical fitness variables among healthy adults. Thus, the aim of this study is to investigate the effects of five weeks of kickboxing training on different physical fitness among young adults.

\section{Materials and methods}

\section{Subjects}

Thirty participants were recruited to participate in the study. In order to eliminate any gender effect, only male subjects were recruited. The Subjects were randomly assigned to a kickboxing training group $(n=15)$ or a control group $(n=15)$. The characteristics of the two groups were (age: $20.9 \pm 1.4$ years, weight: 72.3 $\pm 7.5 \mathrm{Kg}$, height: $1.8 \pm 0.1 \mathrm{~m}$, BMI: $22.7 \pm 2.9 \mathrm{~kg} \cdot \mathrm{m}^{-2}$ and body fat: $12.6 \pm 3.5 \%)$ for kickboxing group and (age: $21 \pm 1.5$ years, weight: $73.1 \pm 8.4 \mathrm{Kg}$, height: $1.9 \pm 0.4$, BMI: $23 \pm 2.8 \mathrm{~kg} \cdot \mathrm{m}^{-2}$ and body fat: $12.8 \pm$ $2.4 \%)$ for control group. The two groups consisted of participants who never had been involved in any combat sports practice. Before the commencement of the study, subjects gave their written consents to participate in the study after explaining to them the risks and benefits of the study and they made a commitment to not participate in other physical activities during the period of training. The study design was approved by the local Ethics Committee and performed in accordance with the MLTJ guideline ${ }^{15}$.

\section{Procedures}

All subjects were tested before and after five weeks of kickboxing training. The athletes were familiarized with test procedures one week before the commencement of the assessments in control days.

All assessments were performed at the same time of day to reduce the effect of diurnal variation on performance. The kickboxing program was performed three times weekly without additional physical conditioning ses- sions for five weeks with each session lasting 1-hour with a qualified kickboxing coach. The training duration was chosen in attempt to verify if a low volume of kickboxing training could bring significant improvement in physical fitness. The daily dietary were maintained as homogeneous as possible for all participants during the training sessions. To monitor the work intensity during the training session, participants' heart rate was recorded using Polar Team System heart rate (HR) monitors, with HR recorded every 5 seconds. The HR monitors were fixed using a roll bandage to prevent any kind of movement or contact, which could impair the operation of the apparatus. After each training session, HR data were downloaded to a computer using the Polar Precision Performance software. The intensity of different sessions was expressed in percentgae of maximal heart rate $\left(\mathrm{HR}_{\mathrm{MAX}}\right)$ and heart rate reserve $\left(\mathrm{HR}_{\mathrm{R}}\right)$ following the two formula:

$\% \mathrm{HR}_{\text {MAX }}=\left(\right.$ session $\left.\mathrm{HR} / \mathrm{HR}_{\mathrm{MAX}}\right) \times 100$

$\% \mathrm{HR}_{\mathrm{R}}=[$ (session HR-resting $\mathrm{HR}) /\left(\mathrm{HR}_{\mathrm{MAX}}\right.$-resting HR) $] \times 100$ (Fig.1).

\section{Kickboxing training program}

The typical kickboxing training session was divided into 4 periods (Tab. 1). The first period was the warmup and the three $(a, b$ and $c)$ remaining ones $(\sim 11 \mathrm{mi}-$ nutes) were divided into bouts of 2-min of specific kickboxing exercices interspersed with 1-min rest. At the end of each period there was a 3-min interval of rest. At the end of these periods, there is a period dedicated for passive rest.

\section{Control group training}

The control group only performed activities including general physical exercises with some recreational sport practice close to physical education classes program for the same period of time with the command of a physical education's teacher. The training

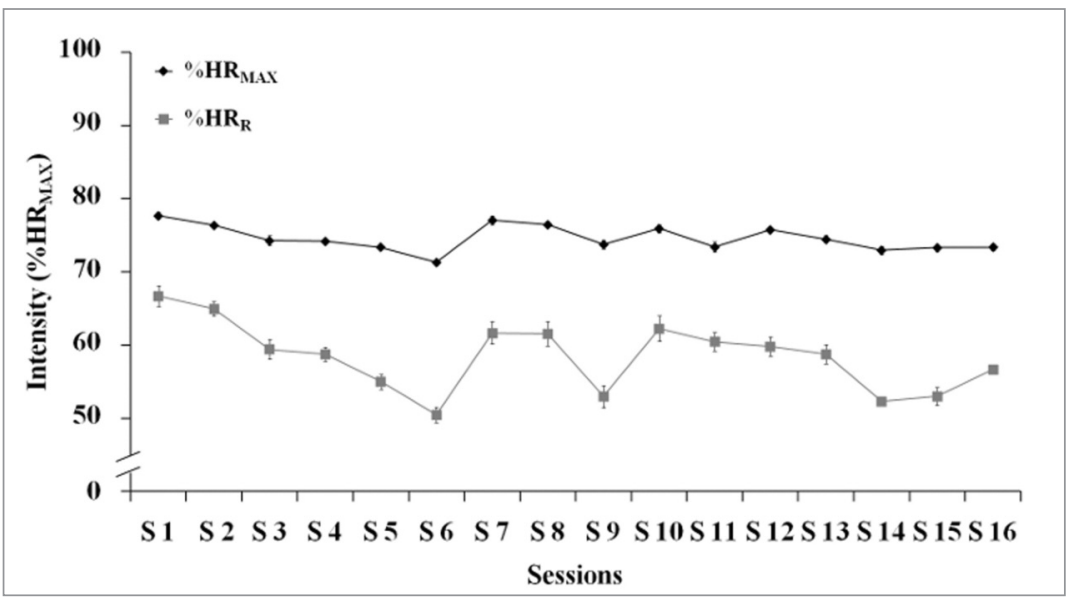

Figure 1. Variability of sessions' intensity during kickboxing training program. 
Table 1. Kickboxing training program.

Phase
Weeknical and tactical training content
We-2 (a) Basic techniques including straight punches, kicks (Roundhouse kick, front kick and sidekick) and defensives
techniques (Slip left, right, Lean backwards and Block/Parry) using different forms of steps (forward, back
and at sideways).
(b) Predefined simple technical combinations between punches and kicks by the commandment of the coach.
(c) Sparring drills: prearranged combat using techniques alternating the role of defending or attacking emphasiz-
ing on long distance combat.
(a) Improvement of offensive and defensive techniques used in nearby distance (Hook, role clockwise and anti-
clockwise).
(b) Sparring drills including attacking and counter attacking.
(c) Prearranged combat including emphasizing defense or attack for nearby distance.
Week 4-5 (a) Shadow sparring using combined offensive and defensive techniques with free steps at different imaginary
targets.
(b) Alternative technical exchange using predefined complex technical combinations by the command of the
coach.
(c) Prearranged sparring based on learning athletes about: reading and reacting, counter attacks, impacting
zones, distancing (week 4) and free sparring in a defined space in a free-moving situation (week 5).

program consisted of a 15 minutes of warm-up period, 9-10 minutes period dedicated to some jogging at moderated intensities intercepted with period of rest. Then, a period of $18<20$ minutes dedicated for some games from different physical activities (e.g., football, basket ball, tennis). The periods of effort were alternated with passive rests. At the end, 10 minutes of rest period dedicated to some muscles stretching exercises and passive rest.

\section{Test procedures}

Progressive maximal exercise test

The progressive maximal cycle ergometer test followed the protocol of Hansen et al. ${ }^{16}$ with measurement of $\mathrm{VO}_{2 \max }$ and maximal aerobic power (MAP) using a breath-by breath analysis system (Quark b2, COSMED, Rome, Italy). During the warm up, the subject pedals for $3 \mathrm{~min}$ at $20 \%$ of its theoretical maximal aerobic power (tMAP) and then the belt load was increased progressively by $8 \%$ of its tMAP every minute. The test was stopped when one or more of the following criteria were met: attainment of a $\mathrm{VO}_{2}$ plateau $<2.2 \mathrm{~mL} \cdot \mathrm{Kg}^{-1} \mathrm{~min}^{-1}$; respiratory exchange ratio $(\mathrm{RER})>1.10$ or the subject was unable to maintain the required pace despite verbal encouragement.

Upper-body Wingate test

Subjects completed one bout of the upper-body Wingate test. Load was set at $4.9 \mathrm{~N} \cdot \mathrm{kg}^{-1}$ of body mass according to a previous study ${ }^{17}$. The test was performed on a Monark cycle ergometer (Monark 894E, Vansbro, Sweden) equipped with handgrips for arm testing. The cycle ergometer was fixed on a table and the subjects were seated on a chair and fixed to avoid any trunc movements. At the start signal, participants were instructed to pedal as fast as they could for 30-s.

\section{Lower-body Wingate test}

The Wingate test was conducted on a calibrated friction loaded cycle ergometer (Monark 894E, Vansbro, Sweden) equipped with toe-clips to prevent the subject's feet from slipping. To avoid an intra-individual effect of postural changes, foot position on the pedals, saddle height, and upper-body position were adjusted to each subject's satisfaction and maintained identical throughout the study. The Wingate test consisted of a 30-s maximal sprint against a constant braking resistance equivalent to $7.5 \mathrm{~N} \cdot \mathrm{kg}^{-1}$. At the start signal, participants were instructed to pedal as fast as they could for 30 -s and instructed to remain seated during the period of test.

\section{Bench press throw test}

The test was conducted using the Myotest device ${ }^{18}$. At the long beep, the subject lowered the barbell right to the chest and remained in a static position. When the device emitted a short beep, the participant drove the barbell up, aiming for maximum velocity by gripping it firmly until full extension of the elbows (the chest may lift off the bench). After the thrust, the arms' position stay extended and in the long beep, the athlete again lowered them into the bent position. After 5 repetitions, the double beep signaled the end of the test.

\section{Medicine ball throw test}

Each subject was seated on an adjustable bench with his back oriented vertically against a back support. Subjects were secured to the bench with elastic strapping placed around the trunk and the back rest at mid chest level under the maxillae to minimize the trunk movements during the put. Subjects were instructed to hold the $5-\mathrm{kg}$ medicine ball $(24 \mathrm{~cm}$ diameter) with both hands, bring the ball up quickly to touch their chest, and then explosively perform a chest-type pass. To facilitate measurement of distance, the skin 
of the medicine ball was lightly dampened to leave an imprint on the floor where first contact was made. Each subject performed 3 trials with 45-s of rest inbetween and the best trial was maintained.

Squat jump test (SJ)

For the SJ, the subjects were instructed to start from a static position of $90^{\circ}$ at the knee angle. Prior to the jump the position was controlled with a manual goniometer. During the jumps, hands were kept on the hips. The SJ test was realized using Myotest device in which the athlete followed the beeps emitted by the device and after 5 repetitions, the double-beep signaled the end of the test ${ }^{18}$.

\section{Countermovement jump test (CMJ)}

During the CMJ, the subject was instructed to rest his hands on his hips while performing a downward movement followed by a maximal effort vertical jump. All subjects were instructed to land in an upright position and to bend the knees following landing. After 5 repetitions, the double-beep emitted by the Myotest device signaled the end of the test ${ }^{19}$.

$10 \times 5 \mathrm{~m}$ shuttle run test

This test was used to assess the speed and agility. Subjects were timed on their ability to sprint as fast as possible 10 times between two lines $5 \mathrm{~m}$ apart.

Sit and reach test

Each subject was seated on the floor with knees fully extended and ankles in neutral dorsiflexion against the calibrated box. The subject was instructed to place one hand on top of the other and slowly reach forward as far as possible while keeping the knees extended. The hands were kept aligned evenly as the subject reached forward along the surface of the calibrated box. The Sit and reach test score (in centimeters) was recorded as the final position of the fingertips on the ruler.

\section{Body composition}

The body composition (i.e., percentage of body fat) was assessed using the skin-fold thickness at four sites-biceps, triceps, sub-scapular and supra-iliac as suggested by 20 .

\section{Statistics}

Data are presented as mean and standard deviation. The homogeneity of variances was checked via Levene's test. The compound symmetry was checked via Mauchly test and a Greenhouse-Geisser correction was used when necessary. A two-way (group and moment) analysis of variance with repeated measurements in the second factor was used to compare variables between groups and moments. A Bonferroni post hoc test was used to identify the differences. Effect sizes were also calculated. The following scale was used for the interpretation of the effect size: [trivial]: < 0.2, [trivial]; 0.2-0.6, [small]; 0.6-1.2, [moderate]; 1.2-2.0, [large]; and $>2.0$, [very large] ${ }^{21}$. The significance level was set in $5 \%$.

\section{Results}

Table 2 presents the aerobic and anaerobic adaptations to the training program in the control and experimental groups.

For the $\mathrm{VO}_{2 \mathrm{MAX}}$, there was an effect of group $\left(\mathrm{F}_{1,28}=\right.$ $7.41, p=0.011, \eta^{2}=0.21$ ), with higher values for the kickboxing group compared to the control group ( $p=$ $0.011)$, and an effect of moment $\left(F_{1,28}=60.43, p<\right.$ $\left.0.001, \eta^{2}=0.68\right)$, with higher values at the end of the program compared to the beginning $(p<0.001)$. There was also an interaction effect $\left(F_{1,28}=58.33, p\right.$ $\left.<0.001, \eta^{2}=0.68\right)$, with the kickboxing training group presenting higher values at post compared to pre and higher values compared to the control group in both moments ( $p<0.001$ for all comparisons).

There was no effect of groups concerning the maximal aerobic power $(P>0.05)$, but there was an effect of moment $\left(F_{1,28}=29.55, P<0.001, \eta^{2}=0.42\right)$, with

Table 2. The effects of kickboxing training program on aerobic and anaerobic variables (mean \pm SD).

\begin{tabular}{|c|c|c|c|c|}
\hline \multirow[t]{2}{*}{ Variables } & \multicolumn{2}{|c|}{ Kickboxing group $(n=15)$} & \multicolumn{2}{|c|}{ Control group $(n=15)$} \\
\hline & Before & After & Before & After \\
\hline$V O_{2 M A X}\left(\mathrm{ml} \cdot \mathrm{min}^{-1} \cdot \mathrm{kg}^{-1}\right)$ & $51.9 \pm 4.3$ & $58.7 \pm 5.2^{* \star *} \mathrm{c}$ & $51.0 \pm 7.8$ & $50.8 \pm 6.7$ \\
\hline Maximal aerobic power $(W)$ & $265 \pm 37$ & $294 \pm 38^{\star \star \star a}$ & $259 \pm 27$ & $261 \pm 21$ \\
\hline Lower-body Wingate peak power $\left(W \cdot \mathrm{kg}^{-1}\right)$ & $9.8 \pm 2.1$ & $10.3 \pm 1.1$ & $10.1 \pm 2$ & $10.3 \pm 2$ \\
\hline Lower-body Wingate mean power $\left(W \cdot \mathrm{kg}^{-1}\right)$ & $6.7 \pm 1.1$ & $7.2 \pm 0.7^{*}$ & $6.5 \pm 0.9$ & $6.5 \pm 0.9$ \\
\hline Lower-body Wingate fatigue index (\%) & $54.4 \pm 7.6$ & $50.4 \pm 5.9$ & $52.5 \pm 9.1$ & $53.2 \pm 8.7$ \\
\hline Upper-body Wingate peak power $\left(W \cdot \mathrm{kg}^{-1}\right)$ & $4.3 \pm 0.7$ & $5.9 \pm 2^{* *} \mathbf{b}, \mathbf{c}$ & $4.3 \pm 0.5$ & $4.4 \pm 0.4$ \\
\hline Upper-body Wingate mean power $\left(W \cdot \mathrm{kg}^{-1}\right)$ & $3.2 \pm 0.7$ & $3.4 \pm 0.7$ & $3.1 \pm 0.7$ & $4.5 \pm 0.7$ \\
\hline Upper-body Wingate fatigue index (\%) & $50.8 \pm 9.1$ & $54.5 \pm 10.8$ & $49.8 \pm 7.6$ & $49.8 \pm 7.8$ \\
\hline
\end{tabular}

${ }^{*} p<0.05^{* *} p<0.01^{* * *} p<0.001$, pre vs post conditions; ${ }^{a} p<0.05^{b} p<0.01^{c} p<0.001$ different from control group at pre and post conditions 
higher values at post compared to pre $(p<0.001)$. The interaction effect $\left(F_{1,28}=29.55, p<0.001, \eta^{2}=\right.$ 0.42 ) indicated that the kickboxing training group achieved higher power outputs in the post training period compared to pre $(p<0.001)$ and compared to the control group in the other two moments ( $p=0.028$ for pre and $p=0.050$ for post).

For lower-body Wingate test peak power, no effects of group, moment or interaction were observed $(p>$ $0.05)$. No effect of group ( $p>0.05$ ) was observed for lower-body Wingate test mean power. However, an effect of moment $\left(F_{1,28}=6.30, p=0.018, \eta^{2}=0.18\right)$ was found, with higher mean power at the post training period compared to pre $(p=0.018)$. An interaction effect $\left(F_{1,28}=4.88, p=0.036, \eta^{2}=0.15\right)$ indicated that only the kickboxing training group improved in the end of the training program $(p=0.015)$. No effect of group or moment $(p>0.05)$ was observed for lower-body Wingate test fatigue index. However, an interaction effect was found $\left(F_{1,28}=2.31, p=0.041, \eta^{2}=0.14\right)$, but the Bonferroni test did not confirm any difference.

For upper-body Wingate test peak power, there was an effect of group $\left(F_{1,28}=7.88, p=0.009, \eta^{2}=0.22\right)$, with higher values for the kickboxing training group compared to the control group ( $p=0.009)$. An effect of moment was also observed $\left(F_{1,28}=8.86, P=0.006\right.$, $\left.\eta^{2}=0.24\right)$, with higher values at post compared to pre $(p=0.006)$. The interaction effect $\left(F_{1,28}=6.80, p=\right.$ $0.014, \eta^{2}=0.20$ ) indicated that the kickboxing at the post presented higher values compared to pre $(p=$ $0.003)$ and to the control group in both moments $(p<$ 0.001 for pre and $p=0.002$ for post). No effects of group, moment or interaction $(p>0.05)$ were observed for upper-body mean power or fatigue index.

Table 3 presents muscle power variables for both groups and the two moments of the training program. An effect of interaction was found for squat jump height $\left(F_{1,28}=5.74, p=0.024, \eta^{2}=0.17\right)$, but the Bonferroni test did not confirm any difference. For the squat jump test, no effect of group, moment or interaction was observed for power, force and velocity $(p$ $>0.05$ ). For the CMJ no effect of group, moment or interaction was found for height, power and velocity $(p>0.05)$. However, an effect of moment was observed for the CMJ force $\left(F_{1,28}=11.26, p=0.002, \eta^{2}\right.$ $=0.29)$, with higher values post compared to pre, as well as an interaction effect $\left(F_{1,28}=4.77, p=0.038\right.$, $\eta^{2}=0.15$ ), with higher values for the kickboxing training group at post compared to pre $(p=0.003)$ and compared to control group at pre $(p=0.003)$ and post $(p=0.015)$.

For the bench press throw power there was an effect of moment $\left(F_{1,28}=24.94, p<0.001, \eta^{2}=0.47\right)$, with higher values post compared to pre. An interaction effect was also observed $\left(F_{1,28}=25.11, p<0.001, \eta^{2}=\right.$ 0.47 ), with higher values for the kickboxing group at post compared to pre $(p<0.001)$ and compared to control group at both pre and post $(p=0.031$ for both comparisons). The velocity achieved during the bench press throw also differed between moments $\left(F_{1,28}=5.03, p=0.033, \eta^{2}=0.15\right)$, with higher values at post compared to pre. An interaction effect $\left(F_{1,28}=\right.$ $\left.5.44, p=0.027, \eta^{2}=0.16\right)$ indicated that only the experimental group improved from pre to post $(p=$ $0.019)$. However, no difference was found concerning force during bench press throw $(p>0.05)$.

For the medicine ball throw, there was an effect of group $\left(F_{1,28}=7.32, p=0.011, \eta^{2}=0.21\right)$, with higher values for the kickboxing group. There was also an effect of moment $\left(F_{1,28}=17.85, p<0.001, \eta^{2}=0.39\right)$, with higher values in the post compared to pre. An interaction effect $\left(F_{1,28}=6.32, p=0.018, \eta^{2}=0.18\right)$ indicated that the kickboxing group at the post training period had better results than itself at pre training $(p$ $<0.001)$ and better than the control group at pre $(p<$ $0.001)$ and post $(p=0.004)$ periods.

Table 4 presents $50-\mathrm{m}$ shuttle run test and flexibility results.

Table 3. Effects of kickboxing training program on muscles power indices (mean \pm SD).

\begin{tabular}{|c|c|c|c|c|c|}
\hline \multicolumn{2}{|c|}{ Variables } & \multicolumn{2}{|c|}{ Kickboxing group ( $n=15)$} & \multicolumn{2}{|c|}{ Control group $(n=15)$} \\
\hline & & Before & After & Before & After \\
\hline SJ & $\begin{array}{l}\text { Height }(\mathrm{cm}) \\
\text { Power }\left(W \cdot \mathrm{kg}^{-1}\right) \\
\text { Force }\left(\mathrm{N} \cdot \mathrm{kg}^{-1}\right) \\
\text { Velocity }\left(\mathrm{m} \cdot \mathrm{s}^{-1}\right)\end{array}$ & $\begin{array}{l}34.4 \pm 2.4 \\
53.1 \pm 4.4 \\
27.8 \pm 3.0 \\
2.58 \pm 0.08\end{array}$ & $\begin{array}{l}30.7 \pm 2.8 \\
55.2 \pm 10.9 \\
27.7 \pm 2.8 \\
2.61 \pm 0.29\end{array}$ & $\begin{array}{l}33.2 \pm 2.1 \\
52.2 \pm 3.9 \\
28.6 \pm 2.7 \\
2.56 \pm 0.07\end{array}$ & $\begin{array}{l}33.8 \pm 2.3 \\
52.3 \pm 3.2 \\
28.7 \pm 3.1 \\
2.57 \pm 0.14\end{array}$ \\
\hline CMJ & $\begin{array}{l}\text { Height }(\mathrm{cm}) \\
\text { Power }\left(W \cdot \mathrm{kg}^{-1}\right) \\
\text { Force }\left(\mathrm{N} \cdot \mathrm{kg}^{-1}\right) \\
\text { Velocity }\left(\mathrm{m} \cdot \mathrm{s}^{-1}\right)\end{array}$ & $\begin{array}{l}36.5 \pm 5.9 \\
59.9 \pm 9.0 \\
30.3 \pm 2.587 \\
2.65 \pm 0.22\end{array}$ & $\begin{array}{l}34.5 \pm 6.8 \\
60.2 \pm 10.6 \\
32.7 \pm 2.5^{\text {** }} \\
2.54 \pm 0.3\end{array}$ & $\begin{array}{l}35.7 \pm 4.1 \\
58.0 \pm 6.1 \\
29.3 \pm 2.9 \\
2.63 \pm 0.21\end{array}$ & $\begin{array}{l}35.1 \pm 4.4 \\
59.5 \pm 7.0 \\
29.8 \pm 1.7 \\
2.62 \pm 0.22\end{array}$ \\
\hline$B P T$ & $\begin{array}{l}\text { Power }(W) \\
\text { Force }(N) \\
\text { Velocity }\left(m \cdot s^{-1}\right)\end{array}$ & $\begin{array}{l}288.2 \pm 42.5 \\
279.1 \pm 14.2 \\
1.31 \pm 0.16\end{array}$ & $\begin{array}{l}325.4 \pm 43.5^{\star \star \star a} \\
288.3 \pm 12.8 \\
1.41 \pm 0.16^{\star}\end{array}$ & $\begin{array}{l}284.9 \pm 30.4 \\
281.9 \pm 16.6 \\
1.32 \pm 0.12\end{array}$ & $\begin{array}{l}284.8 \pm 29.4 \\
282.1 \pm 21.0 \\
1.32 \pm 0.13\end{array}$ \\
\hline \multicolumn{2}{|c|}{ Medicine ball throw test $(m)$} & $4.1 \pm 0.4$ & $4.7 \pm 0.5^{\star \star \star} c, b$ & $3.9 \pm 0.3$ & $4.0 \pm 0.3$ \\
\hline
\end{tabular}

${ }^{*} p<0.05^{* *} p<0.01^{* * *} p<0.001$, pre vs. post conditions; ${ }^{a} p<0.05^{b} p<0.01^{c} p<0.001$ denotes difference from pre and post conditions at control group; $\mathrm{SJ}$ : squat jump; CMJ: countermovement jump; BPT: bench press throw test. 
Table 4. The effects of kickboxing training program on speed and agility and flexibility (mean \pm SD).

\begin{tabular}{|c|c|c|c|c|}
\hline \multirow[t]{2}{*}{ Variables } & \multicolumn{2}{|c|}{ Kickboxing group $(n=15)$} & \multicolumn{2}{|c|}{ Control group $(n=15)$} \\
\hline & Before & After & Before & After \\
\hline $\begin{array}{l}\text { Speed and agility } \\
5 \times 10 \mathrm{~m} \text { shuttle run test (s) }\end{array}$ & $17.3 \pm 1.4$ & $16.2 \pm 1.0^{*} \mathbf{a}, \mathrm{b}$ & $17.9 \pm 0.9$ & $17.8 \pm 0.9$ \\
\hline $\begin{array}{l}\text { Flexibility } \\
\text { Sit and reach test }(\mathrm{cm})\end{array}$ & $15.9 \pm 0.4$ & $18.2 \pm 0.5^{\star} \mathbf{b}$ & $15.6 \pm 0.7$ & $16.0 \pm 0.6$ \\
\hline
\end{tabular}

${ }^{*} p<0.001$, pre vs post conditions; a $p<0.01^{b} p<0.001$ denotes difference from pre and post conditions at control group.

An effect of moment $\left(\mathrm{F}_{1,28}=17.85, \mathrm{p}<0.001, \eta^{2}=\right.$ $0.39)$ was observed for the $5 \times 10-m$ shuttle run test, with higher values post compared to pre. An interaction effect was also found $\left(F_{1,28}=6.32, p=0.018, \eta^{2}=\right.$ 0.18 ), with the kickboxing training group presenting higher values at post compared to pre $(p<0.001)$ and compared to control group at pre $(p<0.001)$ and post $(p=0.004)$.

Flexibility values also differed between moments $\left(F_{1,28}=243.04, p<0.001, \eta^{2}=0.90\right)$, with higher values at post than at pre. An interaction effect $\left(F_{1,28}=\right.$ 115.53, $p<0.001, \eta^{2}=0.81$ ) indicated that the difference was related to the kickboxing training group, which presented higher values at post compared to pre and compared to the control group at both moments ( $p<0.001$ for all comparisons). The body fat percentage, for both experimental and control groups, were $(12.6 \pm 3.5 \%$ and $12.8 \pm 2.4 \%$ respectively before and $(12.6 \pm 3.4 \%$ and $12.9 \pm 2.3 \%$ respectively $)$ after the training period. There was no effect of group $\left(F_{1,28}=0.52, p=0.082, \eta^{2}=0.02\right)$, moment $\left(F_{1,28}=\right.$ $\left.0.504, P=0.58, \eta^{2}=0.02\right)$ or interaction effect $\left(F_{1,28}\right.$ $=0.83, p=0.37, \eta^{2}=0.03$ ).

\section{Discussion}

The findings of the present study revealed that 5weeks of kickboxing training involved significant improvements in aerobic power (i.e., MAP and $\mathrm{VO}_{2 \mathrm{MAX}}$ ), anaerobic fitness (i.e., upper-body peak power and lower-body mean power during the Wingate test) as well as improvements in muscle power (force output during CMJ test, performance in medicine ball and bench press throw tests), sprint and agility and flexibility in comparison to baseline and control group values. Conversely, the body composition, SJ and CMJ performances (i.e., velocity and power) did not show any changes for both groups.

The present study showed that the kickboxing can be a suitable exercise for enhancing cardio respiratory fitness $\left(13.2 \pm 6.0 \%\right.$ and $11.2 \pm 5.9$ respectively for $\mathrm{VO}_{2}$ MAX and MAP). In the scientific literature, there is no consensus about the effect of martial arts training on aerobic fitness because there are many variables (i.e., training intensity, duration and frequency and the aerobic fitness initial levels of the participants) that can bias its effect. Therefore, some studies ${ }^{6,22,23}$ demonstrated that combat sports' training did not show any aerobic improvement, while Toskovic et al. ${ }^{24}$ showed that dynamic taekwondo workout can be a suitable exercise for enhancing aerobic fitness and therefore can be appropriately prescribed for cardiovascular conditioning. Similarly, Yoshimura and Imamura ${ }^{13}$ showed that 30 min of basic karate training during 10-weeks can be an appropriate method for enhancing cardiovascular fitness. Recently, Haddad et al. ${ }^{25}$ have shown that performing repeated taekwondo specific skills increased $\mathrm{HR}$ to the same level, and were perceived as producing the same training intensity as did short-duration interval running in adolescent TKD athletes to enhance aerobic fitness. Concerning our results, the aerobic improvement obtained after the kickboxing training may be associated with the intensity and training frequency. Since the frequency of training sessions (three sessions per week) with the intensity of different training sessions that varied in a range from $71.3 \pm 2 . \%$ to $77.6 \pm 7.6 \%$ of $\mathrm{HR}$ max and $50.51 \pm 5.66 \%$ to $66.7 \pm$ $7.4 \%$ of $\mathrm{HR}_{\mathrm{R}}$ (Fig. 1) were in line with the guidelines for improving $\mathrm{VO}_{2 \mathrm{MAX}}$ which recommend aerobic activity on at least 3 days a week ${ }^{25}$ and that the intensities were in the range capable of improving and/or maintaining cardiorespiratory fitness $(64-95 \%$ of maximal heart rate $)^{26}$ that our training program elicited cardiorespiratory improvement.

In the same way, anaerobic power for both upper and lower-body increased after the training program (upper- body peak power: $42.4 \pm 62.4 \%$ and lower- body mean power: $10.2 \pm 15.9 \%)$. Sterkowicz et al. ${ }^{23}$ showed a significant improvement in anaerobic performance (i .e., time to generate peak power) after judo training. These results can be explained by the fact that the kickboxing is characterized by brief high intensity techniques (punches and kicks) where the effort is probably maintained by the Adenosine Tri Phosphate-Creatine Phosphate system ${ }^{17}$. Furthermore, the greatest anaerobic fitness obtained in our study can be supported by the training type, which is based on the execution, at high intensity, of powerful and repeated techniques simple and combined.

Body fat percentage did not show any decrease after the kickboxing training. Our results are in line with the findings of Tsang et al. ${ }^{12}$ which demonstrated that 6months of kung-fu training was not associated with improvements in body fat percentage. Contrarily, other studies showed that Taekwondo 22,24 and Judo 4 may be a suitable exercise form for fat burn. Despite there is no 
exact evidence why our kickboxing training program did not induce body fat decrease, some possible explanations could explain this fact based essentially on the training duration in our study (5 weeks) in comparison to other training program (12-weeks for) ${ }^{22}$. Moreover, the nature of effort in kickboxing sport (a high solicitation of anaerobic glycolysis) ${ }^{17}$ may can't be a good exercise for weight control. Furthermore, the energy expenditure in training sessions may did not meet the ACSM guidelines $^{27}$ which noticed that exercise which can elicit 300 kcal as energy expenditure for a minimum of 3 days per week could lead to fat loss. One other possible explanation is that, despite the daily dietary were controlled during the days of training, we couldn't control it during the days off training and then the unchangeable body fat percentage may be the result of non controlled nutritional behavior during the training period.

Otherwise, the kickboxing training was sufficient to induce increase in upper-body muscle power (i.e., performance in medicine ball $(13.5 \pm 12.8 \%)$ and bench press throw tests: $13.6 \pm 10.0$ and $8.1 \pm 6.8 \%$ respectively for power and velocity components) and lower-body only for CMJ test (i.e., improvement in the force component by $8.2 \pm 6.7 \%$ ). More likely, specific changes in muscle power may be explained by the fact that training stimulus (i.e., intensity and duration) may caused some neural adaptations (e.g. increases in muscle fiber recruitment, intramuscular coordination) ${ }^{28}$. Furthermore, the most skeletal muscles adaptations for upper than lower body noted in our study can be explained by the specificity of kickboxing where kickboxers tend to use more punches techniques than kicks ${ }^{14}$ and then muscles of upperbody were maybe more solicited than muscles for lower- body.

For the speed and agility, the improvement obtained $(6.5 \pm 5.4 \%)$ may be assigned to specific movements in kickboxing which involves repeated fast stepping and displacements which are characterized by agility and velocity ${ }^{17}$. The improvement in flexibility (14.4 \pm $4.0 \%$ ) after the kickboxing training may be a result of the training's regimen in kickboxing. Coaches make an emphasis on the development of this basic fitness component to handle the technical and tactical aspects of this sport since the kicking in high amplitude can be a good strategy to obtain more points in the score and require the development of muscles and joints flexibility. Thus, the kickboxing training may provide a method for preventing injuries by enhancing muscles flexibility and provide preventive health benefits.

\section{Conclusion}

In conclusion, the present study showed that the kickboxing training induced several benefits for aerobic and anaerobic performances, muscle power, speed and agility and flexibility whereas performance during Wingate upper (mean power) and lower body test (peak power), lower body power in SJ and CMJ (height, power and velocity components) and body composition deemed unchangeable. These findings suggest that kickboxing seems to be not only a method for self defense but also a good way which can provide health promoting and a meaningful exercise for enhancing fitness among young adults. Thus, fitness instructors, strength and conditioning professionals may consider recommending kickboxing to their clients as a beneficial form of exercise to promote physical fitness and for preventing injuries by increasing muscles flexibility.

\section{Acknowledgements}

The authors gratefully thank all athletes who took part in the study.

\section{Competing interests}

The authors declare no conflict of interest related to the present manuscript.

\section{Funding}

This study was financially supported by the Tunisian Ministry of Scientific Research.

\section{References}

1. Cox JC. Traditional Asian Martial Arts Training: A Review Quest. 1993;45(3):366-388.

2. Woodward TW. A review of the effects of martial arts practice on health. Wis Med J WMJ. 2009;108(1):40.

3. Violan MA, Small EW, Zetaruk MN, Micheli LJ. The effect of karate training on flexibility, muscle strength, and balance in 8to 13-year-old boys. Pediatr Exerc Sci. 1997;9(1):55-64.

4. Fukuda DH, Stout JR, Kendall KL, Smith AE, Wray ME, Hetrick RP. The effects of tournament preparation on anthropometric and sport-specific performance measures in youth judo athletes. J Strength Cond Res Natl Strength Cond Assoc. 2013;27(2):331-339.

5. Fong $\mathrm{S}, \mathrm{Ng}$ G. Sensory integration and standing balance in adolescent taekwondo practitioners. Pediatr Exerc Sci. 2012;24(1):142-151.

6. Melhim AF. Aerobic and anaerobic power responses to the practice of taekwon-do. Br J Sports Med. 2001; 35(4): 231-234.

7. Brudnak M, Dundero D, Van Hecke F. Are the 'hard' martial arts, such as the Korean martial art, TaeKwon-Do, of benefit to senior citizens? Med Hypotheses. 2002;59(4):485-491.

8. Cromwell RL, Meyers PM, Meyers PE, Newton RA. Tae Kwon Do: An Effective Exercise for Improving Balance and Walking Ability in Older Adults. J Gerontol A Biol Sci Med Sci. 2007;62 (6):641-646.

9. Pons van Dijk G, Lenssen AF, Leffers P, Kingma H, Lodder J. Taekwondo training improves balance in volunteers over 40. Front Aging Neurosci. 2013;5:10.

10 Fong SSM, Tsang WWN, Ng GYF. Taekwondo training improves sensory organization and balance control in children with developmental coordination disorder: A randomized controlled trial. Res Dev Disabil. 2012;33(1):85-95.

11. Jackson K, Edginton-Bigelow K, Cooper C, Merriman H. A 
Group Kickboxing Program for Balance, Mobility, and Quality of Life in Individuals With Multiple Sclerosis: A Pilot Study. J Neurol Phys Ther. 2012;36(3):131-137.

12. Tsang TW, Kohn M, Chow CM, Singh MF. A randomized controlled trial of Kung Fu training for metabolic health in overweight/obese adolescents: the « martial fitness » study. J Pediatr Endocrinol Metab JPEM. 2009;22(7):595-607.

13. Yoshimura $\mathrm{Y}$, Imamura $\mathrm{H}$. Effects of Basic Karate Exercises on Maximal Oxygen Uptake in Sedentary Collegiate Women. J Health Sci. 2010;56(6):721-726.

14. Ouergui I, Hssin N, Franchini E, Gmada N, Bouhlel E. Technical and tactical analysis of high level kickboxing matches. Int $\mathrm{J}$ Perform Anal Sport. 2013;13(2):294-309.

15. Padulo J, Oliva F, Frizziero A, Maffulli N. Muscles, Ligaments and Tendons Journal. Basic principles and recommendations in clinical and field science research. MLTJ. 2013;4:250-252.

16. Hansen JE, Sue DY, Oren A, Wasserman K. Relation of oxygen uptake to work rate in normal men and men with circulatory disorders. Am J Cardiol. 1987;59(6):669-674

17. Ouergui I, Hammouda O, Chtourou H, Zarrouk N, Rebai H, Chaouachi A. Anaerobic upper and lower body power measurements and perception of fatigue during a kick boxing match. J Sports Med Phys Fitness. 2013;53(5):455-460.

18. Comstock BA, Solomon-Hill G, Flanagan SD, et al. Validity of the Myotest $\circledast$ in Measuring Force and Power Production in the Squat and Bench Press: J Strength Cond Res. 2011; 25(8):2293-2297.

19. Nuzzo JL, Anning JH, Scharfenberg JM. The Reliability of Three Devices Used for Measuring Vertical Jump Height: J Strength Cond Res. 2011;25(9):2580-2590.

20. Durnin J, Womersley J. Body fat assessed from total body density and its estimation from skinfold thickness: measure- ments on 481 men and women aged from 16 to 72 years. $\mathrm{Br} \mathrm{J}$ Nutr. 1974;32(1):77-97.

21. Hopkins WG. A scale of magnitudes for effect statistics. New View Stat. 2002.

22. Kim H-B, Stebbins CL, Chai J-H, Song J-K. Taekwondo training and fitness in female adolescents. J Sports Sci. 2011; 29(2):133-138.

23. Sterkowicz S, Tyka AK, Chwastowski M, Sterkowicz-Przybycień $K$, Tyka A, Klys A. The effects of training and creatine malate supplementation during preparation period on physical capacity and special fitness in judo contestants. J Int Soc Sports Nutr. 2012;9(1):41.

24. Toskovic NN, Blessing D, Williford HN. The effect of experience and gender on cardiovascular and metabolic responses with dynamic tae kwon do exercise. J Strength Cond Res. 2002;16(2):278-285.

25. Haddad M, Chaouachi A, Wong DP, Castagna C, Chamari K. Heart rate responses and training load during nonspecific and specific aerobic training in adolescent taekwondo athletes. J Hum Kinet. 2011;29:59-66.

26. Garber CE, Blissmer B, Deschenes MR, et al. Quantity and Quality of Exercise for Developing and Maintaining Cardiorespiratory, Musculoskeletal, and Neuromotor Fitness in Apparently Healthy Adults: Guidance for Prescribing Exercise. Med Sci Sports Exerc. 2011;43(7):1334-1359.

27. Haskell WL, Lee I, Pate RR, et al. Physical activity and public health: updated recommendation for adults from the American College of Sports Medicine and the American Heart Association. Med Sci Sports Exerc. 2007;39(8):1423.

28. Patten C, Kamen G, Rowland DM. Adaptations in maximal motor unit discharge rate to strength training in young and older adults. Muscle Nerve. 2001;24(4):542-550. 